\title{
A Inserção do Psicólogo no Trabalho de Prevenção ao Abuso de Álcool e Outras Drogas
}

The insertion of the psychologist in preventive works on the abuse of alcohol and other drugs

Resumo: $O$ presente trabalho discute a inserção do profissional de Psicologia no trabalho preventivo ao uso de álcool e outras drogas. Analisa os dados epidemiológicos disponíveis sobre o consumo de drogas no Brasil, que caracterizam o uso abusivo de álcool como um grave problema de saúde pública em nosso país. Mostra que, como em outras parcelas da população, o consumo de álcool e drogas por universitários demanda o desenvolvimento de trabalhos preventivos específicos, descreve uma oficina de redução dos riscos associados ao abuso de álcool por universitários e discute ainda os pressupostos das estratégias preventivas de redução de danos. Finalmente, salienta a importância da inserção do psicólogo nesse trabalho e de sua capacitação, não somente no que diz respeito à prática clínica, mas também à sua atuação no desenvolvimento de trabalhos preventivos.

Palavras-Chave: Psicólogo, prevenção, alcoolismo

Abstract:The present work discusses the insertion of the psychologist in preventive works on the abuse of alcohol and other drugs. Brazilian epidemiological data on drug consumption are analyzed and alcohol abuse is characterized as a serious problem of public health in our country. It is shows that, as in other population segments, university students' alcohol and other drugs abuse requires the development of specific preventive actions. A workshop to reduce the harms associated to alcohol abuse in university

Hilda Regina Ferreira Dalla Déa

Professora titular do Depto. de Psicologia do Desenvolvimento e

coordenadora do Aprimoramento Clínico Institucional $O$ Psicólogo e a Prevencão ao Abuso de Álcool e Outras Drogas (PUC-SP).

Elcio Nogueira dos Santos

Erick Itakura \& Tatiana Bacic Olic

Psicólogo(a), (as) aprimorando(a), (as).

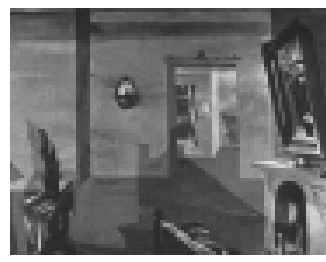
students is described and the fundamental basis of harm reduction strategies are stressed. Finally, the work emphasizes the importance of the psychologist's insertion in this area and the imperative need of technically capacitating psychologists, not only with respect to clinical practice, but also to develop preventive actions. Key Words: Psychologist, prevention, alcoholism.

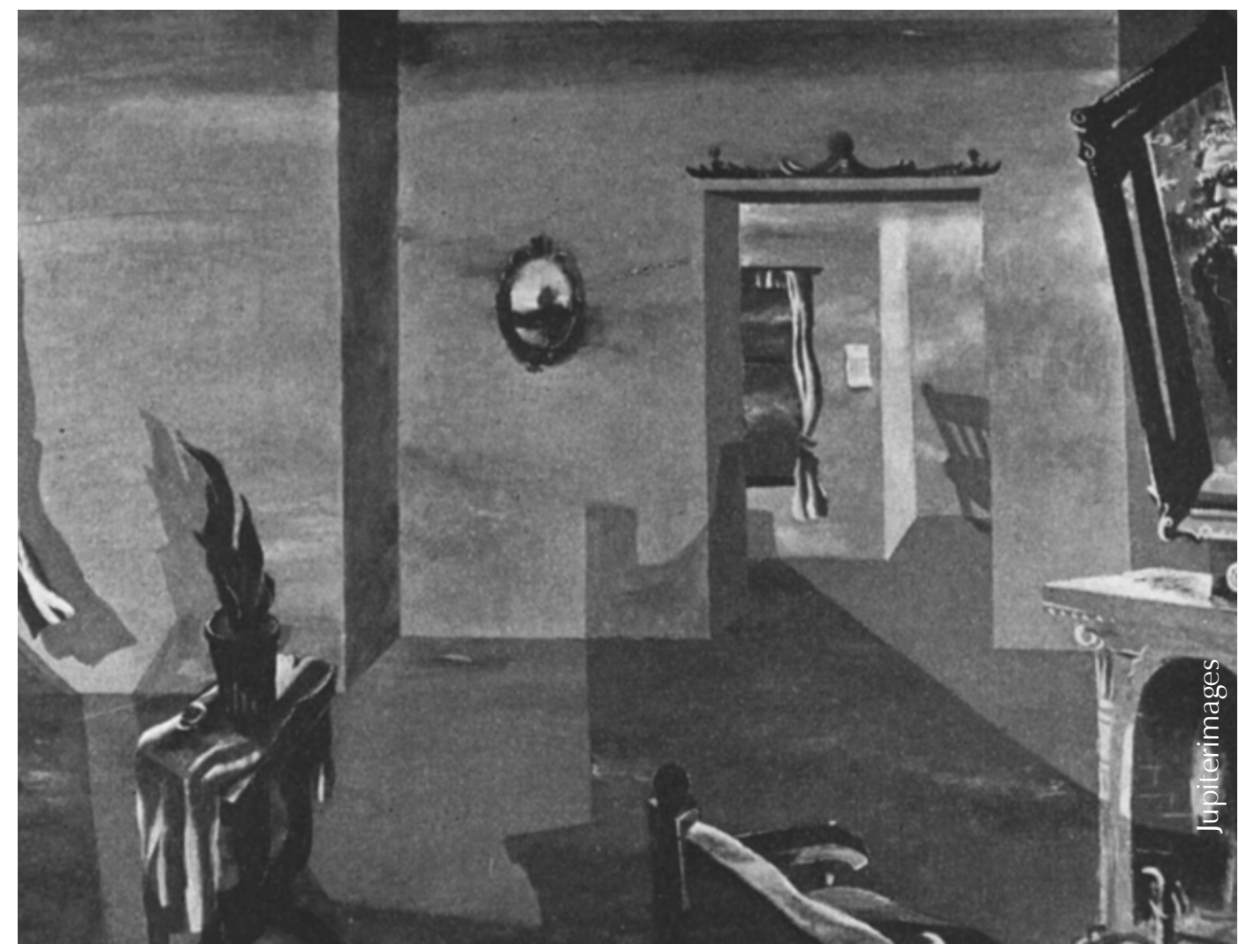




\section{Drogas, Por quê?}

O tema fascina os jovens, angustia os pais e preocupa os educadores. Os meios de comunicação veiculam, diariamente, informações sobre o assunto, muitas vezes num tom dramático, de catástrofe iminente. A literatura científica enfatiza a importância de se enfrentar a questão do abuso de substâncias através de medidas de prevenção adequadas. Por que o uso de drogas vem, cada vez mais, apresentando-se como uma questão do nosso tempo?

O consumo de substâncias psicoativas existe desde os primórdios da história do homem, em praticamente todas as culturas conhecidas. Curiosidade, desejo de transcendência, busca da imortalidade, do prazer, da sabedoria, são alguns dos motivos que aparecem, desde sempre, associados ao desejo por alguma droga.

Drogas ou substâncias psicoativas ${ }^{1}$ “... são aquelas que modificam o estado de consciência do usuário. Os efeitos podem ir desde uma estimulação suave causada por uma xícara de café ou chá até os efeitos ...produzidos por alucinógenos tais como o LSD..." (Seibel e Toscano Jr., 2001, p.1). Masur \& Carlini (1989) definem drogas como substâncias que interferem com o funcionamento dos neurotransmissores, provocando alterações e distúrbios no comportamento.

Ao longo da história da humanidade, o uso de drogas insere-se em vários contextos. Desde o místico, associado aos rituais e à busca de transcendência, até o econômico, do qual a Guerra do Ópio e a economia paralela de países como a Colômbia são alguns exemplos (Totugui, 1988). Em nosso meio, praticamente todas as pessoas fazem uso de algum tipo de droga. Medicamentos, álcool e tabaco são drogas legalmente comercializadas. Cada cultura determina quais drogas devem ser consideradas legais e ilegais. Isso está mais relacionado a aspectos antropológicos e econômicos do que a morais ou éticos, ou mesmo aos efeitos ou características farmacológicas das substâncias em questão (Bucher, 1992).

O aumento verificado nos últimos anos no consumo de drogas dos países desenvolvidos é, sem dúvida, alarmante. Por um lado, o narcotráfico organizou-se de forma mais eficiente, expandindo a oferta de produtos; pelo outro, cresceu a demanda de psicotrópicos por uma parcela cada vez maior da população (Bucher, 1996).

\section{A Dimensão do Problema no Brasil}

Embora no Brasil o padrão de consumo de drogas não seja comparável ao que se verifica nos países desenvolvidos, sua evolução recente torna esse tema uma preocupação obrigatória dos profissionais da área de saúde.

O estudo mais amplo sobre o consumo de drogas no País (Carlini, Galduróz, Noto \& Nappo, 2002) envolveu as 107 maiores cidades do Brasil (com mais de 200 mil habitantes). Foram entrevistadas 8.589 pessoas, com idades de 12 a 65 anos, de todas as classes sociais. Os objetivos desse estudo foram estimar a prevalência do uso e da dependência de drogas lícitas e ilícitas, além de avaliar a percepção da população sobre as drogas, a facilidade de obtê-las, seus efeitos e seus riscos. Seus resultados retratam o comportamento dos brasileiros que moram nas grandes cidades: para o álcool, o uso na vida ${ }^{2}$ foi relatado por $69 \%$ dos sujeitos pesquisados e a prevalência de dependentes foi estimada em $11 \%$, maior nos homens $(17 \%)$ do que nas mulheres $(6 \%)$.

Em relação ao tabaco, o uso na vida é de $41 \%$, e o número de dependentes chega a $9 \%$ da população. A maconha já foi utilizada por $7 \%$ dos entrevistados, os solventes por $6 \%$ e a cocaína por $2 \%$ dos sujeitos estudados.

Chamam a atenção as diferenças de comportamento entre homens e mulheres. Embora todos sejam expostos da mesma maneira ao consumo de drogas, com o tempo, os homens passam a usar muito mais essas substâncias do que as mulheres. No caso do álcool, um em seis homens torna-se dependente. Já para as mulheres, essa razão é de uma para dezessete.

\section{As Drogas mais Usadas pelos Estudantes Brasileiros}

O estudo de Galduróz, Noto e Carlini (1997) reúne os resultados obtidos nos quatro levantamentos sobre o consumo de drogas psicoativas por alunos do ensino médio e fundamental em dez capitais brasileiras, realizados pelo CEBRID (Centro Brasileiro de Informações sobre Drogas Psicotrópicas) em 1987, 1989, 1993 e 1997.

Segundo esse estudo, o álcool é a droga mais amplamente utilizada pelos estudantes, muito à frente do segundo colocado, o tabaco. O uso de álcool tem início bastante precoce na vida desses jovens - cerca de $50 \%$ dos alunos entre 10 e 12 anos já fizeram uso dessa droga. $\mathrm{O}$ uso freqüente e o uso pesado ${ }^{3}$ vêm aumentando na maioria das capitais estudadas. Quase 30\% dos estudantes já
1 Embora o termo "droga" tenha um sentido mais geral, referindose a qualquer substância exógena que altere a fisiologia normal do organismo e os termos "droga psicotrópica" e "substância psicoativa" refiram-se especificamente àquelas substâncias que interferem com o funcionamento do sistema nervoso central, os três termos são utilizados normalmente como sinônimos.

2 Uso na vida: quando a pessoa fez uso de uma droga pelo menos uma vez em toda a vida World Health Organization, 1980).

3 Uso freqüente : quando a pessoa utilizou droga seis ou mais vezes nos trinta dias que antecederam a pesquisa; uso pesado: quando a pessoa utilizou droga vinte ou mais vezes nos trinta dias que antecederam a pesquisa World Health Organization, 1980). 
utilizaram bebidas alcoólicas até embriagar-se. No último levantamento (1997), 11\% da população pesquisada relatou ter brigado e 19,5\% faltado à escola depois de beber. Quando comparado a drogas como maconha, cocaína, heroína ou tabaco, o álcool é a substância cujo uso crônico leva a maior risco orgânico, entendendo-se como risco não só a probabilidade de ocorrência de problemas, mas também a sua gravidade (Masur \& Carlini, 1989). Os principais danos orgânicos associados ao uso crônico de álcool são gastrite (em geral, é o problema que aparece mais cedo), aumento da pressão arterial, pancreatite, miocardite, hepatite e cirrose alcoólica, distúrbios neurológicos graves, alterações da memória e lesões no sistema nervoso central.

Entretanto, ao contrário dos efeitos orgânicos decorrentes do uso crônico de cocaína ou mesmo do tabaco, os danos associados ao álcool levam um tempo mais longo para aparecer, da ordem de cinco a dez anos. Por isso, raramente encontramos jovens alcoolistas, embora o aumento de consumo de álcool que vem ocorrendo nas faixas etárias mais baixas possa modificar essa situação.

O uso inicial de tabaco também é bastante precoce, sendo que, aos 10-12 anos de idade, cerca de $12 \%$ já experimentaram essa substância. Há tendência de aumento no uso freqüente e no uso pesado em quatro das dez cidades estudadas.

Os inalantes são substâncias presentes em produtos industrializados como esmalte, cola de sapateiro, corretivos de tinta, fluidos de isqueiro, lançaperfume, entre outros. Em todos os levantamentos realizados, os inalantes só foram superados pelo álcool e pelo tabaco. Freqüentemente associado a populações marginalizadas, como meninos em situação de rua, o uso de inalantes tem sido muitas vezes compreendido como uma resposta a condições de vida extremamente precárias. Entretanto, como salientam Dalla-Déa, Almeida, Silveira e Toledo (1999), o uso dessas substâncias por jovens de classe média indica que esse fenômeno não se restringe à influência de fatores como a fome, a miséria e a marginalização, mas também é influenciado por pressões de grupo e por aspectos da subjetividade do usuário e de seus conflitos, tanto individuais quanto familiares.

No último dos quatro levantamentos (Galduróz, Noto e Carlini 1997), a maconha mostrou uma tendência de aumento do uso na vida. O uso freqüente e o uso pesado também cresceram significativamente. Os autores sugerem que esses resultados podem ser interpretados de duas maneiras: ou o uso dessa substância realmente aumentou, ou a mudança de atitude da sociedade frente à maconha, possibilitando os atuais debates sobre a sua descriminalização e seu uso terapêutico fez com que os jovens passassem a relatar mais freqüentemente seu uso, que sempre foi elevado.

Nos quatro levantamentos realizados, os ansiolíticos e os anfetamínicos (moderadores do apetite) sempre apareceram entre as drogas mais consumidas pelos estudantes, com uma utilização nitidamente maior no sexo feminino. Em algumas capitais, há tendência para o aumento do uso freqüente e do uso pesado de ambos os tipos de drogas. Por se tratar de substâncias que reconhecidamente induzem a dependência ${ }^{4}$, seu uso sem controle médico é potencialmente perigoso. Além disso, muitos casos de anorexia nervosa iniciam-se após a utilização de anfetamínicos em regimes conduzidos incorretamente.

O uso de cocaína vem-se popularizando entre os estudantes - das dez capitais estudadas, apenas no Rio de Janeiro e em Recife não se observou tendência de aumento do uso na vida. O uso freqüente cresceu em oito capitais (inclusive em São Paulo). Da mesma forma, o uso pesado apresentou aumento em quase todas as capitais. Por outro lado, o uso de "crack" aparece muito raramente - as baixas porcentagens para uso de "crack" entre os estudantes possivelmente significam que, como a dependência do "crack" é sempre muito severa, aqueles que começam a usar essa droga perdem rapidamente o vínculo com a escola.

Mesquita, Bucaretchi, Castel e Andrade(1995), em seu estudo sobre o uso de substâncias psicoativas por estudantes da Faculdade de Medicina da USP, verificaram que o álcool é a droga mais usada, com taxas de prevalência de uso na vida de $82 \%$, uso no ano, $76 \%$ e uso no mês, $69 \%$. De maneira geral, o álcool é a droga que mais conta com a aprovação dos alunos, tanto em relação à experimentação quanto ao uso regular.

Andrade, Bassit, Kerr-Corrêa, Tonhon, Boscovitz, Cabral, Rassi, Potério, Marcondes, Oliveira, Dualibi e Fukushima (1997) avaliaram o consumo de drogas em 5225 alunos de nove escolas de Medicina do Estado de São Paulo. Os resultados confirmam os achados do trabalho anterior - a droga mais usada foi o álcool, seguida pelo tabaco, solventes, maconha, tranqüilizantes e cocaína. Não foram encontradas diferenças entre os estudantes da capital e do interior.

Um estudo preliminar sobre o uso de bebidas alcoólicas por estudantes de Psicologia da PUC$\mathrm{SP}$ e suas atitudes em relação ao álcool ${ }^{5}$ obteve resultados semelhantes, porém mais elevados do 
que os trabalhos anteriormente citados - o uso na vida foi relatado por $97 \%$, o uso no ano por $95 \%$ e o uso no mês por $79,9 \%$ dos sujeitos. A maioria $(75,1 \%)$ relata já ter bebido até a embriaguez, e $23,3 \%$ ter-se embriagado no último mês.

O conjunto desses resultados mostra que a prevalência do uso de álcool e outras drogas por adolescentes e adultos jovens é mais elevada do que a observada na população geral. Assim, a adolescência e o início da vida adulta caracterizam-se como um dos períodos de vulnerabilidade aumentada - uma "janela de risco". Devido a fatores subjetivos e/ou culturais, nesses períodos (a terceira idade é um deles) ocorre um aumento da probabilidade de consumo de álcool ou outras drogas e, portanto, dos problemas associados a esse consumo.

\section{Entre a Cervejinha e o Alcoolismo}

O álcool é uma droga legalizada e seu consumo não só é aceito pela sociedade como incentivado por intensa propaganda. Entretanto, é importante salientar que o uso pesado de bebidas alcoólicas é o caminho mais curto para o alcoolismo. Calculase que 10 a $12 \%$ da população mundial é dependente de álcool, o que caracteriza o uso abusivo de bebidas alcoólicas como um grave problema de saúde pública em todo o mundo. No Brasil, o álcool é responsável por mais de 90\% das internações por dependência química, e está associado a mais da metade dos acidentes de trânsito, principal causa de morte na faixa etária de 16 a 20 anos. O álcool é, seguramente, a droga que mais danos traz à sociedade como um todo. Além disso, no caso particular de adolescentes e jovens, o consumo de álcool também está diretamente relacionado a doenças sexualmente transmissíveis, uso de outras drogas, abuso sexual, baixo desempenho escolar, danos ao patrimônio, comportamento violento e confrontos entre gangues.

Quando ingressa na universidade, o jovem transpõe uma fase de sua vida, "deixa de ser adolescente" e inicia uma nova vida, "mais adulta". Nesse momento, o contexto sociocultural pode funcionar como reforçador para o consumo de bebidas alcoólicas, que representa um dos aspectos do mundo adulto. Dessa maneira, o "calouro" universitário é estimulado, pelo grupo, a beber. A bebida assume um caráter não só de integração, mas também de socialização desse estudante no universo acadêmico, tido como formador do jovem para a vida adulta. Além disso, fatores relacionados à dinâmica psíquica podem contribuir decisivamente para o consumo de doses cada vez maiores de álcool pelos jovens universitários, como, por exemplo, dificuldades no relacionamento com os pais e/ou relacionamentos afetivos, dificuldades financeiras etc.

Assim, o uso abusivo de álcool por adolescentes e adultos jovens constitui um sério problema de saúde pública cuja prevenção, para ser efetiva, deve levar em consideração tanto fatores socioculturais quanto aspectos da subjetividade do jovem. Por isso, o trabalho preventivo envolve não só a ação educativa, mas implica também uma psicoprofilaxia, uma atitude clínica, no sentido mais amplo do termo.

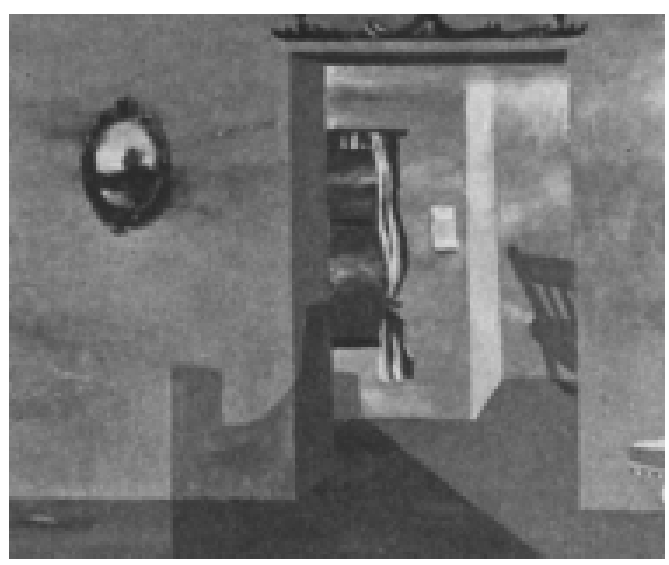

Quando destinado a estudantes das áreas de saúde e educação, esse trabalho reveste-se ainda de uma importância adicional. Nesse caso, os aspectos formativos são prioritários, uma vez que os profissionais dessas áreas irão se deparar, no seu trabalho cotidiano, direta ou indiretamente, com questões relacionadas ao uso/abuso ${ }^{6}$ de drogas. Em São Paulo, a USP e a UNESP vêm desenvolvendo programas preventivos ao uso de álcool e outras drogas em seus campi. Por iniciativa da Secretaria Nacional Antidrogas (SENAD), vem sendo desencadeada a Campanha Nacional Antidrogas nas escolas superiores. Essa campanha tem o apoio técnico do Grupo Interdisciplinar de Estudos de Álcool e Drogas (GREA) e é coordenada pelo Centro de Integração Empresa-Escola (CIEE). Essas iniciativas indicam que a questão do uso de drogas por estudantes universitários começa a ser percebida, em nível nacional, como relevante.

Alguns indicadores, como o grande número de bares instalados ao redor dos campi universitários, as cervejadas patrocinadas por fabricantes de bebidas, o atendimento médico a jovens embriagados e a presença de traficantes nas proximidades dos campi mostram que o uso abusivo de álcool e drogas por universitários demanda um trabalho preventivo específico.
6 Fala-se em abuso ou uso abusivo de uma substância quando seu uso passa a ocasionar problemas (orgânicos, psicológicos ou sociais) ao usuário. 


\section{A Prevenção ao Uso Abusivo de Álcool}

O uso abusivo de álcool não começa na universidade, mas representa a continuidade e, por vezes, o agravamento de um padrão de uso estabelecido anteriormente. A grande maioria dos jovens abandona o hábito de beber pesadamente e supera os problemas relacionados ao álcool sem assistência ou tratamento, porém, enquanto isso não acontece, eles são vulneráveis a uma miríade de conseqüências perigosas. Por isso, um objetivo importante dos programas de prevenção deve ser ajudar os jovens a atravessar mais seguramente essa janela de risco.

O enfoque de redução de danos, difundido em nosso país a partir da epidemia de AIDS, vem sendo ampliado para outros comportamentos de risco, como abuso de álcool e outras drogas. A redução de danos lida, de modo efetivo, com indivíduos que têm algum tipo de comportamento de risco, e opta pela saúde e pela responsabilidade pessoal, ao invés da doença e da punição. Pode ser aplicada a toda a população que se distribui ao longo de uma escala contínua de risco - de baixo a moderado e alto.

A redução de danos configurou-se, nos Países Baixos, como uma política definida "de baixo para acima", baseada na defesa do dependente. Não surgiu através de políticas autoritárias, formuladas pelos órgãos oficiais. Para o uso e a dependência de drogas, o modelo de redução de danos representa uma alternativa de saúde pública para os modelos moral/ criminal e de doença. Assume o fato de que muitas pessoas usam drogas e promove acesso a serviços de baixa exigência. Sua idéia central é encontrar o indivíduo onde ele está, e não onde ele deveria estar (Marlatt, 1999). Por isso, embora reconheça a abstinência como resultado ideal, a redução de danos aceita alternativas que possam reduzir os danos associados ao uso de drogas.

Embora possam reconhecer que seu padrão de uso de álcool leva a certos perigos ou riscos, os jovens que bebem excessivamente podem ser incapazes de reduzir seu consumo e controlar esses riscos. Para isso, precisam desenvolver estratégias e habilidades para neutralizar as pressões que os motivam a beber. Programas que os auxiliem a desenvolver essas estratégias e habilidades podem modificar significativamente seu comportamento de beber de alto risco.

Dimeff, Baer, Kivlahan \& Marlatt (1998) desenvolveram, na Universidade de Washington, Seattle, um programa de triagem e intervenção breve para bebedores de alto risco (BASICS - Brief
Alcohol Screening and Intervention for College Students), que obteve como resultado uma redução significativa dos problemas associados ao uso de álcool e dos sintomas de dependência ao álcool. Estudos longitudinais mostraram que essa redução se manteve mesmo após cinco anos da participação no programa.

Esse programa leva em consideração aspectos do desenvolvimento, aspectos motivacionais e elementos de informação. É um programa de redução de danos, portanto, seu objetivo primário não é a abstinência ou a diminuição do uso de bebidas alcoólicas, mas a redução dos comportamentos de risco e dos danos produzidos pelo álcool.

Os principais pressupostos que nortearam o desenvolvimento do BASICS são sintetizados a seguir:

alguns momentos do desenvolvimento contribuem para o beber em excesso, como, por exemplo, o início de uma nova fase na vida escolar e o afastamento da família.

fatores que mantêm o comportamento de beber excessivamente nos jovens são diferentes dos que mantêm esse comportamento nos adultos.

Fatores pessoais (como mitos sobre o álcool) e fatores sociais (pressão do grupo, convivência com amigos que bebem muito) contribuem para o uso excessivo de bebidas alcoólicas e devem ser levados em conta no delineamento de ações preventivas.

metas definidas pelos próprios jovens em relação ao seu comportamento de beber são mais efetivas do que os objetivos estabelecidos ou cobrados pelos outros.

A redução dos riscos associados ao uso abusivo de álcool é, em si mesma, um objetivo válido para uma intervenção preventiva.

\section{"Bebidas alcoólicas - vamos destilar essa idéia?"}

A partir dos pressupostos acima, desenvolvemos a oficina "Bebidas alcoólicas - vamos destilar essa idéia?" como parte das atividades do Aprimoramento Clínico Institucional "O Psicólogo e a Prevenção ao Abuso de Álcool e Outras Drogas", da Clínica Psicológica Ana Maria Poppovic, da Faculdade de Psicologia da PUC-SP.

Seu objetivo é reduzir os riscos associados ao uso excessivo de bebidas alcoólicas pelos estudantes que acabaram de ingressar na universidade, de 
modo a auxiliá-los a atravessar mais seguramente essa janela de risco, conforme o sentido atribuído acima.

A população-alvo foi constituída pelos alunos do primeiro ano da Faculdade de Psicologia da PUCSP em 2001. A partir de um trabalho de divulgação feito em sala de aula, 28 alunos inscreveram-se para participar da oficina.

A oficina compõe-se de quatro módulos de duas horas de duração. O primeiro módulo consiste em um sociodrama tematizado no qual os participantes são solicitados a criar e dramatizar uma história relacionada ao álcool. A técnica utilizada foi a retramatização, que consiste essencialmente em um trabalho coletivo cuja efetivação depende de contribuições individuais. Na retramatização, a partir de pensamentos e sentimentos individuais (tramas), os participantes trabalham em grupos na criação de um texto sociodramático (retramas), utilizando os recursos teatrais e dramáticos (Liberman, 1995).

Essa atividade tem por objetivo trabalhar a vivência subjetiva de situações que envolvam o uso e/ou o abuso de bebidas alcoólicas pelos jovens, preservando a intimidade individual, mas com acesso a ela. Nem sempre a comunicação verbal expressa a realidade dos fatos relatados. Por outro lado, durante uma vivência dramática, ocorre uma forte mobilização afetiva que cria um clima de compromisso, dificilmente conseguido quando se utiliza apenas a comunicação verbal (Santos,1997). "O tema possibilita que cada um enxergue, em cada papel sociodramático, alguma faceta individual e, como em um caleidoscópio, forme uma visão, uma imagem crítica, emocionada e iluminada pela cena dramática (Liberman, 1995, p. 39).

A prática do sociodrama compreende três etapas: aquecimento, dramatização e comentários. O trabalho começa pelo aquecimento, que possibilita uma acomodação prévia das pessoas para a ação. A dramatização é a ação propriamente dita, que pode consistir em um jogo, uma colagem, uma montagem etc., de acordo com a técnica utilizada. "O comentário é a etapa do compartilhar, do processamento afetivo e técnico do que foi sentido, percebido e vivido" (Santos, 1997, p.93). O sociodrama e o psicodrama utilizam essencialmente as mesmas técnicas, mas, no sociodrama, o protagonista é sempre o grupo.

No segundo módulo, é feito um trabalho com grupos de seis a oito pessoas, sob a coordenação de um dos psicólogos aprimorandos. Nesses grupos, são mapeados e trabalhados os aspectos trazidos à tona no módulo anterior.
No terceiro módulo, os participantes são os convidados de uma "festa virtual" ${ }^{7}$, que simula as situações geralmente encontradas em festas, como beber, dançar e namorar. O objetivo dessa atividade é familiarizar os participantes com a possibilidade de administrar o uso de bebidas alcoólicas, tentando minimizar os riscos decorrentes da ingestão de álcool. Isso pode ser obtido através do conhecimento das relações entre os efeitos do álcool, sua dinâmica no organismo e sua concentração no sangue.

No último módulo, são explicitados e discutidos conceitos relativos ao uso do álcool, sua fisiologia e seus efeitos. Finalmente, os participantes são estimulados a fazer uma avaliação pessoal de sua relação com o álcool e, se considerarem necessário, a modificar essa relação. O que se pretende é favorecer a integração dos aspectos afetivos vivenciados no sociodrama aos aspectos cognitivos, trabalhados a partir da festa virtual, de modo que os participantes aumentem sua percepção tanto dos riscos associados ao abuso de bebidas alcoólicas quanto das possibilidades de reduzi-los.

\section{Avaliação dos Resultados}

Durante o sociodrama, evidenciou-se a importância, para os participantes, do efeito desinibidor produzido pelas bebidas alcoólicas, especialmente em situações de convívio social, como festas e "baladas". Nessa atividade, o uso de bebidas alcoólicas apareceu associado ao uso de outras drogas (maconha, ácido, êxtase), brigas, acidentes de carro e sexo não planejado.

Todos esses aspectos foram discutidos no segundo encontro, quando foi realizado o trabalho com os grupos. Nessa atividade, também foi trabalhada a preocupação dos participantes com o papel do profissional da saúde em relação a essa questão.

Por suas características lúdicas, a "festa virtual" foi a atividade mais apreciada pelos alunos. Quando inquiridos sobre o que haviam aprendido com ela, vários alunos referiram-se a aspectos como: diferenças entre homem e mulher em relação aos efeitos do álcool e teor alcoólico das diferentes bebidas. Vários perceberam que muito do que supunham ser conhecimento sobre o álcool não passava de "mito", como o de que café sem açúcar ou banho frio curam bebedeira, entre outros.

Ficaram interessados em compreender os fatores que influenciam a taxa de álcool no sangue e surpreenderam-se ao perceber como duas pessoas que bebem a mesma quantidade de álcool podem atingir concentrações sangüíneas diferentes, em função do seu sexo e/ou de seu peso.

\section{"O tema possibilita \\ que cada um enxergue, em cada papel sociodramático, alguma faceta individual e, como em um caleidoscópio, forme uma visão, uma imagem crítica, emocionada e iluminada pela cena dramática"}

Liberman
7 Nessa versão das oficinas, foi utilizada a "festa virtual" encontrada no link "Álcoole drogas" do site do Hospital Israelita Albert Einstein (http:-) Lwww.einstein.br), baseado no CD ROOM Alcohol 101, produzido em 1997 pelo The Century Council, entidade não-governamental norteamericana, em parceria com a Universidade de IllinoisChampaign.

8 Gíria utilizada atualmente por jovens para referir-se a festas onde o consumo de álcool e outras drogas pode ser facilitado. 
No último encontro, essas questões conceituais foram discutidas e esclarecidas, e alguns participantes já relataram modificações em seu comportamento de beber em função da participação na oficina. O trabalho como um todo foi avaliado de forma muito positiva pelos participantes.

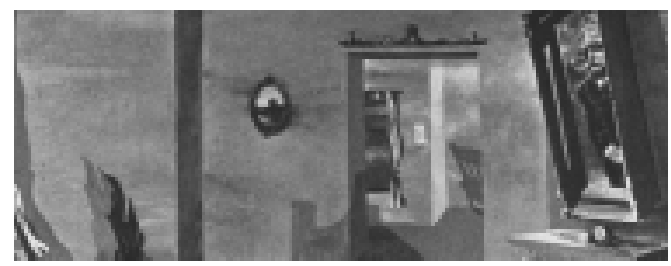

\section{Discussão e Conclusões}

Um primeiro aspecto a chamar a atenção foi o interesse dos alunos em participar da oficina, que pode estar relacionado, ao menos em parte, à estratégia utilizada na divulgação do trabalho, que salientou o papel do psicólogo frente à questão do uso abusivo de álcool.

As atividades interativas revelaram-se instrumentos de importância crucial para o trabalho preventivo. Por outro lado, a ênfase na redução dos danos associados ao uso de álcool, e não nos possíveis distúrbios ocasionados por seu uso, fez com que as atividades se livrassem do "peso" que, muitas vezes, se associa ao trabalho de prevenção.

Através do sociodrama, os participantes se sensibilizaram para a relação entre aspectos subjetivos e sua forma de usar o álcool. Este manteve sua função socializadora, pois houve uma festa, mesmo que virtual, na qual o trabalho se desenvolveu com características lúdicas e em clima de descontração, o que favorecia a percepção mais clara dos riscos e das possibilidades de reduzi-los.

Outro aspecto digno de nota relaciona-se à aderência relativamente alta dos participantes ao trabalho, que, ao contrário do inicialmente previsto, não pôde ser desenvolvido em quatro semanas consecutivas, pois, em dois dos horários planejados para a oficina, os alunos foram solicitados pela faculdade a resolver questões de matrícula. Dessa forma, o trabalho acabou estendendo-se até meados de junho, período pouco favorável ao desenvolvimento desse tipo de atividade em função da proximidade do término do semestre letivo. Apesar disso, boa parte dos alunos continuou participando da oficina até o seu final.

O presente trabalho mostra que, quando estimulado a problematizar sua relação com o álcool de forma reflexiva e não punitiva, o jovem interessa-se em conhecer melhor os efeitos do álcool sobre seu organismo e os riscos que seu uso abusivo pode acarretar. Envolve-se também na reflexão sobre sua própria forma de lidar com as bebidas alcoólicas e a possibilidade de modificá-la, de modo a reduzir os riscos sociais e pessoais do uso abusivo de álcool. O trabalho mostrou ainda que, para estudantes da área de Psicologia, essa atividade remete a uma reflexão relativa ao seu futuro papel como profissionais da área de saúde no trato com essa questão.

A "oficina de álcool" revela claramente as potencialidades do desenvolvimento de estratégias preventivas adaptadas à nossa realidade a partir dos princípios básicos da redução de danos. Salienta ainda a contribuição essencial das técnicas e recursos da Psicologia e a urgência da capacitação de profissionais dessa área para o desenvolvimento de estratégias de prevenção ao uso abusivo de álcool e outras drogas.

Consideramos a oficina de álcool o passo inicial para o desenvolvimento de outros projetos na área de prevenção, pois, ao nosso ver, hoje a práxis do psicólogo não se restringe ao atendimento clínico, mas é de suma importância para o desenvolvimento de ações psicoprofiláticas no campo social e no da saúde pública.

\section{Considerações finais}

O uso abusivo de álcool por adolescentes e adultos jovens vem-se constituindo, cada vez mais, em sério problema de saúde pública em nosso país. O uso de bebidas alcoólicas é estimulado por intensa propaganda e seu abuso é socialmente tolerado e, às vezes, até estimulado. Embora socialmente aceito, o beber excessivo traz uma série de riscos que raramente são reconhecidos como tal, especialmente na adolescência. Por isso, atividades preventivas que favoreçam o reconhecimento desses riscos e o desenvolvimento de estratégias para minimizá-los assumem um caráter de relevância e urgência em nosso país.

Ao levar em conta não só os fatores socioculturais como aspectos da subjetividade do jovem, esse de tipo trabalho preventivo envolve não só uma ação educativa, mas implica também uma psicoprofilaxia, uma atitude clinica, no sentido mais amplo do termo. A importância crucial da atuação do psicólogo nessa área aponta claramente para a necessidade de capacitação dos profissionais de Psicologia para esse tipo de trabalho preventivo e para o diálogo com profissionais de outras áreas em equipes multidisciplinares voltadas para a promoção de saúde. 
Hilda Regina Ferreira Dalla Déa, Elcio Nogueira dos Santos, Erick Itakura \& Tatiana Bacic Olic Rua Inácio de Araújo, 20 apto 81/3 - Mooca E-mail: hildareg@terra.com.br 03053-010 SÃO PAULO-SP

ANDRADE, A.G., BASSIT, A.Z., KERR-CORRÊA, F., TONHON, A.A., BOSCOVITZ, P.E., CABRAL, M., RASSI, R., POTÉRIO, G.M., MARCONDES, E., OLIVEIRA, M.P.M.T., DUAILIBI, K. \& FUKUSHIMA, J.T. Fatores de Risco Associados ao Uso de Álcool e Drogas na Vida, Entre Estudantes de Medicina do Estado de São Paulo.Rev. ABPAPAL, 19(4),1997, pp.117-26.

BUCHER, R. Drogas e Drogadição no Brasil. Porto Alegre: Artes Médicas, 1992.

Bucher, R. Drogas e Sociedade nos Tempos da Aids. Brasília: Ed. Universidade de Brasilia,1996.

CARLINI, E.A., GALDURÓZ, J.C.F., NOTO, A.R. \& NAPPO, S.A. Levantamento Domiciliar sobre o Uso de Drogas Psicotrópicas no Brasil: Estudo Envolvendo as 107 Maiores Cidades do País - 2001. São Paulo: CEBRID - Centro Brasileiro de Informações sobre Drogas Psicotrópicas - UNIFESP - Universidade Federal de São Paulo,2002.

DALLA-DÉA, H.R.F, ALMEIDA F., SILVEIRA, M.T. \& TOLEDO, V.C. Você já Cheirou Lança-perfume? Um Estudo Sobre o Uso de Inalantes por Alunos das Escolas Públicas de Bairros de Classe Média da Cidade de São Paulo. Psic.Rev.São Paulo, 8,1999,pp.23-40.

DIMEFF, L. A., BAER, J. S., KIVLAHAN, D. R. \& MARLAT, G. A. Brief Alcohol Screening and Intervention for College Students - A Harm Reduction Approach. London/New York: The Guilford Press, 1998.

GALDURÓZ, J.C., NOTO, A.R, CARLINI, E.A. I Levantamento Sobre o Uso de Drogas Entre Estudantes de $1^{\circ} \mathrm{e} 2^{\circ}$ Graus em 10 Capitais Brasileiras.São Paulo: CEBRID - Centro Brasileiro de Informações sobre Drogas Psicotrópicas. Departamento de Psicobiologia da Escola Paulista de Medicina - UNIFESP - Universidade Federal de São Paulo,1997.
GALDURÓZ, J.C.F., NOTO, A.R. Uso Pesado de Álcool Entre Estudantes de $1^{\circ}$ e $2^{2}$ Graus da Rede Pública de Ensino em Dez Capitais Brasileiras. J. Bras. Dep. Quím. 1(1),2000, pp.25-31.

LIBERMAN, A. Retramatização - a Trama Individual, a Retrama Grupal e a Ação Dramática Como Agente de Transformação: uma Proposta Sociodramática. Rev. Bras. de Psicodrama, 3(2),1995,pp.25-39.

MARLATT, G.A. Redução de Danos - Estratégias Práticas Para Lidar com Comportamentos de Alto Risco. Trad. Daniel Bueno. Porto Alegre: Artes Médicas, 1999.

MASUR, J. \& CARLINI, E.A. Drogas - Subsídios Para uma Discussão. São Paulo: Brasiliense, 1989.

MESQUITA, A.M.C., BUCARETCHI, H.A., CASTELI, S. \& Andrade, A.G. Estudantes da Faculdade de Medicina da Universidade de São Paulo: Uso de Substâncias Psicoativas em 1991. Rev.ABP-APAL , 17(2), 1995,pp. 47-54.

ORGANISATION MONDIALE DE LASANTÉ. Comité d'Experts de la Pharmacodependence. Série de Rapports Techniques, $n^{\circ} 407$. Genève, 1969.

SANTOS, R.M.S. Prevenção de Drogas na Escola - Uma Abordagem Psicodramática. Campinas: Papirus,1997.

SEIBEL, S.D. \& TOSCANO,Jr. A. Conceitos Básicos e Classificação Geral das Substâncias Psicoativas. In Seibel, S.D. \& Toscano Jr.A (eds.), Dependência de Drogas. São Paulo: Atheneu,2001,pp.1-6.

TOTUGUI, M.L. Visão Histórica e Antropológica do Consumo de Drogas. In Bucher, RO. (org.). As Drogas e a Vida - Uma Abordagem Biopsicossocial. São Paulo: CORDATO-EPU,1988,pp.1-7.

WORLD HEALTH ORGANIZATION. A Methodology for Student Drug-use Surveys. WHO Offset Publication, $n^{\circ}$ 50. Geneve,1980. 